\title{
Determining the possibility of placing turbine systems for hydraulic regulation and production of electrical energy in the District Heating Network in Krakow
}

\author{
Piotr Natkaniec ${ }^{1}$, Piotr Dzierwa ${ }^{2}$ \\ ${ }^{1}$ Municipal Thermal Energy Enterprise S.A. (MPEC S.A.) in Krakow, Jana Pawła 188, 30-969 Krakow, Poland \\ ${ }^{2}$ Department of Thermal Engineering and Air Protection, Faculty of Environmental and Energy Engineering, Cracow University of \\ Technology, Warszawska 24, 31-155 Krakow, Poland
}

\begin{abstract}
This article presents the methods of specifying the potentiality of energy recovery in the turbine installations projected to hydraulic regulation of the heating medium in the Krakow District Heating System. To achieve this, creating hydraulic calculations enabling to indicate the best places to install turbines in District Heating System is necessary. For this reason, a great amount of work - like choosing a methodology and optimal calculation program, creating an actual database for calculations - has to be done. Hydraulic calculations will also help to determine optimal parameters of future instalments, select the most suitable devices necessary for the proper working of turbine installations and create the future impact assessment to District Heating System.
\end{abstract}

\section{Introduction}

The primary goal of the Municipal Thermal Energy Enterprise S.A. (MPEC S.A.) in Krakow is to provide thermal comfort to the inhabitants of Krakow (which is the second largest city in terms of the number of inhabitants in Poland) and Skawina. Krakow's District Heating Network, which is approximately $915 \mathrm{~km}$ long [1], has a high demand for heat for residential or commercial requirements. Heat is produced in three outside sources: PGE Energia Ciepła S.A., Elektrownia Skawina S.A. and Waste Incineration Plant (ZTPO). Through municipal heat distribution network, thermal energy reaches 10770 substations [1], wherein counter current heat exchangers heat energy from district heating system (primary side) is transferred to the lowtemperature heating, hot water supply, ventilation and technological systems of residential and industrial buildings (secondary side).

Due to the need to provide thermal comfort for each recipient, including the one furthest away from the heat sources, the supply of a heating medium with appropriate thermal and hydraulic parameters should be ensured. The size of the heating networks of the city of Krakow, the considerable distance and the difference in the terrain height between heat sources and recipients located in different places of the heat supply create the need to order variable and suitably high pressure and thermal parameters from the heat suppliers.

\section{Methods of regulation of the heating medium parameters in Krakow's District Heating Network}

\subsection{Thermal regulation}

The parameters of the heating medium in heat sources are regulated based on temperature tables and pressure parameters specified in contracts between MPEC S.A. and heat consumer.

During the heating season, the temperature ordered at heat sources depends on external atmospheric conditions and is in the range from $70^{\circ} \mathrm{C}$ to $135^{\circ} \mathrm{C}$ for an external temperature of $-20^{\circ} \mathrm{C}$.

In the summer season, the supply temperature is maintained at a constant level of $70{ }^{\circ} \mathrm{C}$. This minimum temperature value results from the necessity to provide the appropriate parameters for the production of domestic hot water and supplying ventilation, airconditioning and technology devices.

\subsection{Hydraulic regulation}

Maximum values of ordered pressures in the heat sources result from the necessity of ensuring required available pressures in the most unfavourable, from the hydraulic point of view, points of the heating network. At the same time, the ordered pressures must take into account the necessity of securing appropriate pressure levels in the return pipes so that at the highest points of the district heating network the pressure value is not less than $0.05[\mathrm{MPa}]$ and in the areas where objects supplied 
from direct heat substations are located the pressure value does not exceed $0.6[\mathrm{MPa}]$. Delivery of the heating medium to the final recipient, apart from the control methods described above, is also affected by the operation of the weather control system installed in the heat substations. The policy of modernization of heat substations adopted by MPEC S.A., consisting in replacing worn-out substations without automation with exchange substations with full weather automation, led to almost complete automation of the heating system. These activities were one of the elements of the Intelligent Heat Distribution Network system in Krakow, which is currently being designed.

\section{Potential possibilities of heating medium energy recovery by using turbine devices}

\subsection{Problems caused by high heating medium pressure}

Due to flow variability caused by quantity and quality regulation, the size of the district heating network and differences in altitude of the feeding areas, there are excess pressures in the district heating system. To limit this phenomenon and to reduce the pumping energy, a pressure control system was applied in the areas supplied by the sources of PGE Energia Ciepła and CEZ Skawina, due to their large extent. The purpose of the regulation is to ensure the minimum required available at network points with the most unfavourable hydraulic conditions. As a supplementary element, a local pressure regulation system was applied in the main networks.

The control methods described above are intended to optimise heat supply on a district heating system-wide scale. However, they are not always sufficient. In the district heating network, especially in areas close to the source, there are high-pressure levels and overdispatching pressures. The available pressure must be generated at the source at a sufficiently high level to be able to supply heat to all consumers. However, highpressure levels have a negative effect on the operation of branches and district heating substations close to the heat sources. When high available pressures and low heating flows occur at the same time, especially during warmer weather in the heating season and in summer, large disturbances are created in the hydraulic systems in the nodal points and networks, causing pressure oscillations that can lead to the undesirable reciprocating movements of the pipelines, which results in the destruction of the heating infrastructure. Reducing the pressure in the heating network can lead to an extension of the life of the district heating infrastructure and enable the system to work under more favourable operating conditions.

For this reason, the idea was conceived to reduce the high values of the available pressure, which are not necessary for the proper operation of the substation and which cause problems in the operation of the district heating system, and to utilise the excess energy.

\subsection{How to use the energy of heating medium movement}

The most common and simple method of recovering the energy of water movement is the use of a water turbine usually connected to an electric generator. This connection can be direct or using a gearbox unit. Thus, we can talk about the use of the so-called hydrogenerator in which in the first stage (in a water turbine) water energy is converted into mechanical energy and then (in a generator) into electrical energy that is convenient for direct use. The effective (or useful) fall of water is used in the described turbine system. In the case under consideration, this effective fall can be defined as the excess of the available pressure occurring in the district heating network.

The theoretical value of power that can be obtained in the case of a heating network can be determined from the dependence:

$$
\mathrm{P}_{\mathrm{t}}=\gamma \cdot \mathrm{Q} \cdot \mathrm{H}_{\mathrm{u}}
$$

where:

$\mathrm{P}_{\mathrm{t}}$ - theoretically possible power [W];

$\gamma$ - specific gravity of a liquid $\left[\mathrm{N} / \mathrm{m}^{3}\right]$;

$\mathrm{Q}$ - volumetric flow rate of water $\left[\mathrm{m}^{3} / \mathrm{s}\right]$;

$\mathrm{H}_{\mathrm{u}}$ - useful (net) fall or pressure excess [ $\left.\mathrm{m} \mathrm{H}_{2} \mathrm{O}\right]$.

Determination of the amount of useful fall $\mathrm{Hu}$, i.e. the actual surplus of available pressure, is possible after detailed hydraulic calculations. Correct calculation of the excess pressure value will make it possible to determine the justification for using the turbines and the amount of energy that can be recovered.

After taking into account various types of losses occurring in the energy transformation process and assuming that $\gamma=\rho \cdot g$, equation (1) can be written as:

$$
\mathrm{P}=\mathrm{P}_{\mathrm{t}} \cdot \eta_{\mathrm{e}}=\rho \cdot \mathrm{g} \cdot \mathrm{Q} \cdot \eta_{\mathrm{e}}=\mathrm{M} \cdot \mathrm{g} \cdot \eta_{\mathrm{e}}
$$

where the new, introduced quantities mean:

$\mathrm{P}$ - system power [W];

$\rho$ - water density $\left[\mathrm{kg} / \mathrm{m}^{3}\right]$;

$\mathrm{g}$ - acceleration due to gravity, $\mathrm{g}=9.81\left[\mathrm{~m} / \mathrm{s}^{2}\right]$;

$\mathrm{M}$ - mass flow rate of water $[\mathrm{kg} / \mathrm{s}]$;

$\eta_{\mathrm{e}}$ - energy conversion efficiency.

The actual power of the hydro unit is lower than the theoretical power due to losses that were taken into account by the efficiency of the system. The quantity determining the efficiency of the system consists of:

- water turbine efficiency $\eta_{\mathrm{t}}$ (averaging $\eta_{\mathrm{t}}=0.8-0.9$ );

- generator efficiency $\eta_{\mathrm{g}}$ (which can be estimated within the limits of $\eta_{\mathrm{g}}=0.85-0.98$ );

- efficiency of the power electronics converter system $\eta_{p}$ (it is within the range $\eta p=0.97-0.99$ )

(the efficiency values given above refer to powerful machines).

The efficiency of energy conversion is equal to the product of the efficiency of individual devices of the system, i.e .:

$$
\eta_{\mathrm{e}}=\eta_{\mathrm{t}} \cdot \eta_{\mathrm{g}} \cdot \eta_{\mathrm{p}}
$$


It should also be said that the efficiency of the turbine itself consists of the following efficiencies: volumetric (volumetric) $\eta_{\mathrm{v}}$, hydraulic $\eta_{\mathrm{h}}$ and mechanical $\eta_{\mathrm{m}}$. The product of the theoretical power $\mathrm{P}_{\mathrm{t}}$, determined from relation (1) and the turbine efficiency

$$
\eta_{\mathrm{t}}=\eta_{\mathrm{v}} \cdot \eta_{\mathrm{h}} \cdot \eta_{\mathrm{m}}
$$

is the useful (effective) power of the turbine received from the shaft of this machine:

$$
P_{u}=P_{t} \cdot \eta_{t}=\gamma \cdot Q \cdot \eta_{t}=M \cdot g \cdot \eta_{t}
$$

Various water turbine systems are currently used to convert water energy into mechanical energy (useful work in the rotor). Of the three forms of water energy present in the hydraulic gradient (according to Bernoulli's equation) in water turbines, potential energy (difference of drops, i.e. pressures) and kinetic energy (water velocity) are used.

Considering the use of turbines as overpressure reduction systems, the use of so-called reaction turbines should be considered. In these devices, the water pressure at the entrance to the rotor blades is higher than atmospheric and decreases during the flow through the inter-blade spaces of the rotor. As the water flows through the impeller, the pressure energy is transformed into additional kinetic energy so that the water in the impeller is accelerated. The impeller for this type of turbine is supplied with water around its entire circumference, which flows through it in a continuous stream and is fed to the outlet via a suction pipe. Literature analyses [2] suggest that suitable recuperative machines, characterised by high efficiency in useful ranges of flows and pressures for water and heating networks, would be solutions using a turbine system with a propeller or Francis rotor.

\subsection{The crucial role of hydraulic calculations}

As mentioned in the previous section, determining the parameters of the heating medium and the amount of excess available pressure that will be possible to use without deteriorating the level of heat supply to consumers is the key point of the discussed topic. This goal can be achieved provided that hydraulic calculations are made based on information about the infrastructure of the heating network and verified measurement data.

Hydraulic calculation programs are used to determine and forecast the operating parameters of the heating network. In Krakow, the information necessary to make calculations is drawn from a modern IT system EC.GIS built on the GE Smallworld platform. In addition to recording and managing the Company's network assets and creating various statistical analyses, the basic module of the system allows the generating and export of information necessary for the creation of an appropriate database in the calculation program.

The first stage of work, which enables hydraulic calculations to be carried out, is the creation of a suitable database based on the information obtained from the registration system EC.GIS. This information includes data on the municipal heating system, e.g. lengths and diameters of pipelines, ground ordinates and the thermal capacities of the connected district heating substations for central heating, domestic hot water, ventilation and air conditioning, among others. The database must then be calibrated, i.e. the results of the calculations must be adjusted as necessary to the actual values for both the heating season and the summer in order to obtain the most accurate information possible on the energy recovery potential of hot water. It is also necessary to compare the calculation results with the measured values at the heat sources and at key locations in the district heating system during the period when the ambient temperature and the heating medium temperature and flow parameters are stable. Obtaining a correct database in accordance with the actual parameters makes it possible to obtain reliable information on the operation of the network system by performing hydraulic calculations.

\subsubsection{Graphical representation of the calculation results}

The possibilities of recovering the surplus energy contained in the flowing water in the heating network can be concluded based on the analysis piezometric graphs created in the calculation program. These charts show the water pressure distribution in the supply and return pipes. They take into account the geodetic profile of the area along the route of the heat network. As mentioned in the previous point of the study, to ensure the proper operation of the heating network and to ensure the supply of heat to each recipient, it is necessary to ensure appropriate pressure values in the supply and return pipelines as well as an appropriate available pressure level. To determine the excess pressure in the network, it was assumed that the available pressure necessary for the proper operation of the district heating substation is 0.2 [MPa]. An example of a piezometric graph with the recoverable pressure level marked is shown in Figure 1.

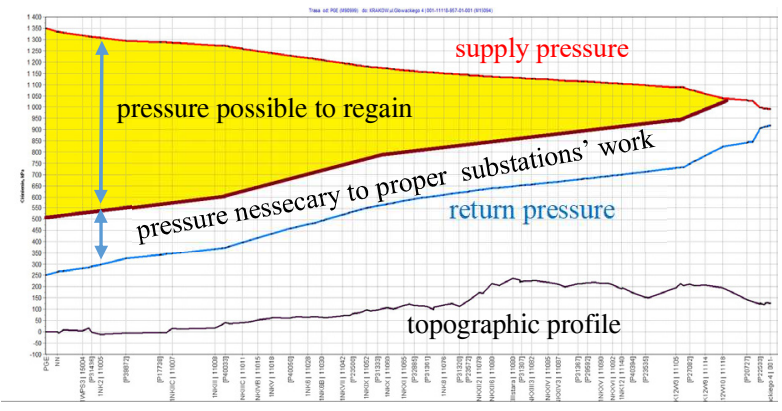

Fig. 1. Example of piezometric graph from the heat source to the recipient with the lowest additional pressure value.

\subsubsection{Tabular presentation of calculation results}

Apart from the graphical presentation of pressure distribution in the district heating network, to accurately determine the amount of available pressure surplus on the scale of the entire district heating system, tabular lists of heating medium parameters have to be prepared based on hydraulic calculations, both on a unit basis, i.e. 
with reference to heat distribution centres, and on an aggregate basis, creating accumulated values up to the level of heat chambers from which consumers are supplied.

This presentation of the results is based on the methodology adopted for selecting sites for the future assembly of turbine systems. Based on experience with interference caused by high pressures in the vicinity of heat sources and to ensure heat supply to each customer, it has been assumed that main transmission pipelines (main networks) should not be subjected to pressure throttling. In the initial phase of turbine installation, two variants of turbine system assembly should be applied:

- in heating chambers on branches supplying more than 5 heating substations,

- individually on connections to heat consumers in the case where a smaller number of nodes is supplied from the main chamber.

Of course, these are assumptions that can be modified depending on the actual conditions and individual requirements.

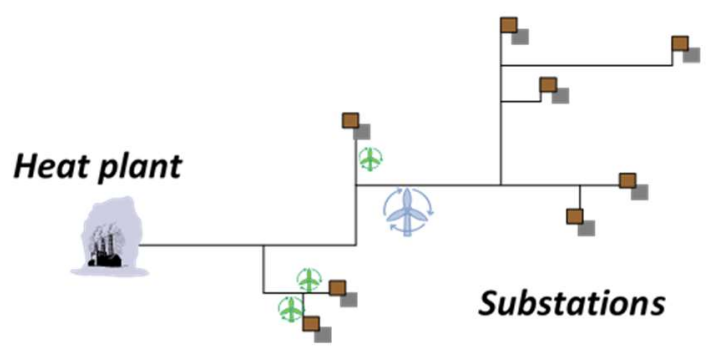

Fig. 2. The ideological assumptions for the assembly of turbine systems.

The figure 2 shows examples of installation locations for turbine installations on the heating network. The green colour indicates installations of lower power installed at direct connections to the heating substation. The blue colour shows the units of higher power turbines installed at branches of heating chambers from which a greater number of heat substations is supplied.

Described methods of turbine assembly were used to tabulate the calculation results. The spreadsheet contains the basic information about the heat chambers substations and hydraulic parameters of the heating medium: supply and returns pressure, available pressure, the pressure required for proper operation of substations, flow. The summary was prepared for the operating conditions for the heating season and the summer period. The analysis covered heating chambers from areas for which the available pressure is greater than $0.5[\mathrm{MPa}]$. For lower available pressure values in the network, throttling the pressure is not recommended. The spreadsheets contain calculation results related to both the level of the district heating node and cumulated to the level of collective heating chambers.
Table 1. A fragment of an example sheet with basic information about the chambers and parameters of the heating medium.

\begin{tabular}{|c|c|c|c|c|c|}
\hline $\begin{array}{c}\text { Heat } \\
\text { chamber }\end{array}$ & $\begin{array}{c}\text { Type of } \\
\text { chamber }\end{array}$ & $\begin{array}{c}\text { branch } \\
\text { diameter }\end{array}$ & $\begin{array}{c}\text { available } \\
\text { pressure } \\
\text { [MPa] }\end{array}$ & $\begin{array}{l}\max . \\
\text { flow } \\
{[\text { t/h] }}\end{array}$ & $\begin{array}{l}\min . \\
\text { flow } \\
{[t / h]}\end{array}$ \\
\hline 1ZKV18 & $\begin{array}{c}\text { Brick } \\
\text { chamber }\end{array}$ & 200 & 0,68 & 35,12 & 5,00 \\
\hline 1ZKV19 & $\begin{array}{c}\text { Brick } \\
\text { chamber }\end{array}$ & 150 & 0,67 & 15,87 & 1,04 \\
\hline 1ZKV20 & $\begin{array}{c}\text { Brick } \\
\text { chamber }\end{array}$ & 250 & 0,66 & 61,58 & 14,30 \\
\hline 1ZKV21 & $\begin{array}{c}\text { Brick } \\
\text { chamber }\end{array}$ & 250 & 0,66 & 100,82 & 18,13 \\
\hline 1NKIIIA & sump & 100 & 0,97 & 16,96 & 2,08 \\
\hline 1NKIIIC & $\begin{array}{c}\text { sump } \\
\text { and } \\
\text { chamber }\end{array}$ & 200 & 0,93 & 84,68 & 14,57 \\
\hline $1 \mathrm{NKIV} / 1 \mathrm{~A}$ & sump & 200 & 0,91 & 33,32 & 5,19 \\
\hline
\end{tabular}

\section{Conclusions}

This study demonstrated the validity and feasibility of using turbine systems to reduce unfavourable excess dispatch pressures while using the mechanical energy of the heating medium to generate electricity. Hydraulic calculations make it possible to identify suitable locations for the installation of these systems and show the level of energy that can be recovered. Furthermore, in addition to pressure reduction, the hydraulic regulation of district heating networks can be a benefit with these systems, which will increase the culture of the district heating system. In addition, thanks to energy conversion, these installations will be able to be used as a source of electricity in heating chambers where the connection of electricity is not feasible.

To sum up, turbine systems may become an important element of the district heating network system MPEC S.A. in Krakow.

\section{References}

1. Municipal Thermal Energy Enterprise S.A. in Krakow - Annual Report, 9, (2020)

2. S. Michałowski, J. Plutecki : Energetyka Wodna, WNT, Warszawa, (1975) 